\title{
Intertextualidade multimodal como estratégia argumentativa
}

\author{
Multimodal intertextuality as an argumentative strategy
}

\author{
Amanda Heiderich Marchon ${ }^{1}$ \\ Carlos Eduardo Nunes Garcia ${ }^{2}$
}

\begin{abstract}
Resumo: A intertextualidade, considerada um dos grandes temas a que se têm dedicado tanto os pesquisadores da Linguística Textual quanto os estudiosos da Análise do Discurso, é um recurso linguístico-discursivo que se refere à construção de novos textos e/ou de novos sentidos a textos que já foram construídos anteriormente, podendo, pois, figurar como importante estratégia argumentativa. À luz da Teoria Semiolinguística do Discurso (CHARAUDEAU, 2009; 2016; 2018), que defende a existência de um sujeito intencional que perpassa a relação linguagem-mundo, associada a alguns pressupostos da Teoria Multimodal da Comunicação (KRESS; VAN LEEUWEN, 2006 [1996]), que defende a ideia de que os sentidos são produzidos por diversos modos semióticos, propomos analisar a intertextualidade multimodal constitutiva do gênero meme. Para tanto, nosso corpus de análise é formado por seis memes sobre questões políticas nacionais da contemporaneidade, cotejados da seção de imagens do Google. Análises qualitativas pautadas simultaneamente no contexto e no cotexto nos levaram a concluir que a mecânica argumentativa engendrada para a produção desse gênero mobiliza o conhecimento de outros textos e, muitas vezes, a leitura de imagens e palavras.
\end{abstract}

Palavras-chave: Intertextualidade. Multimodalidade. Argumentação. Meme.

\begin{abstract}
Intertextuality is a theme that researchers from Textual Linguistics and Discourse Analysis area have been dedicated to. Intertextuality is a linguistic-discursive resource that refers to the construction of new texts and / or new meanings to texts that were previously built and it can be an important argumentative strategy. Considering the Semiolinguistic Discourse Theory (CHARAUDEAU, 2009; 2016; 2018), which defends the existence of an intentional subject that permeates the world-language, associated with some assumptions of the Multimodal Theory of Communication (KRESS; VAN LEEUWEN, 2006 [1996]) which defends the idea that the senses are built on different semiotic ways, we propose to analyze a multimodal intertextuality constituting the genre "meme". Our analysis is constituted of six memes about contemporary national policies took from the Google images section. The Qualitative analysis, considering the context and cotext, led us to conclude that the argumentative mechanics mobilized on the production of this textual genre mobilizes the knowledge of other texts and, frequently, the reading of images and words.
\end{abstract}

Keywords: Intertextuality. Multimodality. Argumentation. Meme.

\footnotetext{
${ }^{1}$ Universidade Federal do Espírito Santo, Departamento de Línguas e Letras, Programa de Pós-Graduação em Linguística, Vitória, ES, Brasil. Endereço eletrônico: amandahch.letras@gmail.com.

2 Centro Federal de Educação Tecnológica de Minas Gerais, Campus Leopoldina, Leopoldina, MG, Brasil. Endereço eletrônico: nunes_carlosedu@ hotmail.com.
} 


\section{Palavras Iniciais}

As ações de linguagem que realizamos diariamente são sempre permeadas por intenções e argumentatividade (KOCH, 2008). O indivíduo, ao interagir por meio da linguagem, o faz visando a estabelecer relações, causar efeitos, desencadear determinados comportamentos. Em última instância, o ser humano quer quase sempre agir sobre o outro; tenta convencê-lo ou intenta persuadi-lo. Pensar a respeito da argumentação é se perguntar, portanto, até que ponto o homem é capaz de influenciar os demais, em maior ou menor grau, por meio das possibilidades de construção de seu discurso.

Sobre as várias possibilidades de construção de um discurso que se pretende argumentativo, à luz da associação de pressupostos da Teoria Semiolinguística do Discurso (CHARAUDEAU, 2009; 2016; 2018) e da Teoria Multimodal da Comunicação (KRESS; VAN LEEUWEN, 2006 [1996]), buscaremos fazer uma descrição da mecânica argumentativa constitutiva do gênero meme, a fim de mostrarmos como o enunciador pode valer-se de estratégias diversas para agir sobre o enunciatário. Por tratarmos a argumentação como uma prática social, entendemos que é importante determinar não somente o gênero e os modos de organização discursiva do corpus de análise, mas as condições de produção da enunciação, que não são apenas linguísticas, mas, sobretudo, situacionais. É por meio da situação de comunicação que podemos observar melhor como os jogos de manipulação e de contramanipulação são engendrados nas trocas linguageiras.

Nesse viés, entendemos, portanto, que o ato argumentativo não pode ser analisado a não ser em função das restrições impostas pela situação comunicativa e em função da identidade social e discursiva dos interlocutores. Com esse balizamento em mente, cotejamos, da seção de imagens do Google, seis memes sobre questões políticas nacionais que suscitaram inúmeras discussões em noticiários e redes sociais entre o final de 2020 e o início de 2021. Mais especificamente, discutiremos temas relacionados às ações das autoridades brasileiras no que tange ao combate à pandemia de Covid-19 e à corrupção.

Para tanto, além desta parte introdutória, nosso trabalho se divide em mais três seções. Na seção subsequente, apresentamos os principais postulados teóricos da Semiolinguística mobilizados nas análises aqui propostas, além de tecermos considerações sobre a Teoria Multimodal da Comunicação. Entendendo que a multimodalidade permeia todo e qualquer discurso, discutimos, em seguida, os conceitos de intertextualidade multimodal (GARCIA, 2020), bem como considerações sobre o gênero meme. Logo depois, procedemos à análise do corpus, procurando desvelar, por meio de elementos verbais e imagéticos, o projeto 
argumentativo do enunciador. Por fim, em nossas considerações finais, sintetizamos as discussões por nós empreendidas.

\section{A Teoria Semiolinguística do Discurso}

Alicerçada nos postulados bakthinianos de alteridade e dialogismo, bem como na noção de enunciação de Benveniste (2006), a Teoria Semiolinguística do Discurso, criada pelo linguista francês Patrick Charaudeau, na década de 1980, insere o discurso numa problemática que procura relacionar questionamentos internos (construção de sentido e do texto) e externos (lógica das ações e influência social) ao fenômeno linguístico. Numa visão nitidamente pragmática, Charaudeau (2009) propõe que a linguagem emerge para satisfazer certas intenções vindas dos sujeitos em interação e para produzir efeitos por meio de seu uso.

No que se refere à argumentação, Charaudeau (2016) a entende como uma prática social e a inscreve num circuito que ele chama de problemática da influência. Segundo esse dispositivo, o enunciador não busca comprovar uma dada verdade, mas levar o interlocutor a crer em uma dada verdade. Em outras palavras, não basta ao sujeito enunciador produzir um discurso verdadeiro, mas é necessário que o discurso produza um efeito de verdade, fazendo com que o interlocutor interprete e acredite nas ideias e nos fatos expostos na atividade discursiva. É por essa razão que o linguista afirma que a situação de comunicação fornecerá as pistas necessárias à produção e à interpretação adequadas dos enunciados, visto que os sentidos são coconstruídos pelos sujeitos envolvidos na troca comunicativa.

Buscando revelar a maneira pela qual as formas da língua são organizadas para atender determinadas demandas que vêm de circunstâncias particulares em que se realiza o discurso, o autor explica que o modo argumentativo de organização do discurso obedece a uma lógica segundo a qual existe uma relação de causalidade entre duas proposições, relação essa instanciada ou não na superfície textual por meio de diferentes marcas formais. Charaudeau (2009, p. 203) ressalta que "a argumentação não se limita a uma sequência de frase ou proposições ligadas por conectores lógicos", uma vez que "o aspecto argumentativo de um discurso se encontra frequentemente no que está implícito”. Nesse viés, índices imagéticos também atuam na construção da argumentação e podem, portanto, ser compreendidos como um exemplo dessa marca formal a que o linguista francês faz menção - Silva e Marchon (2021) denominam de argumentação multimodal o processo em que diferentes semioses são empregadas com finalidade argumentativa. 
A charge de Benett a seguir, publicada em abril de 2021, no jornal Folha de São Paulo, ilustra claramente a relação de causalidade característica do modo argumentativo e o fenômeno de argumentação multimodal, pontos sobre os quais nos referimos no parágrafo anterior.

Figura 1 - Charge de Benett

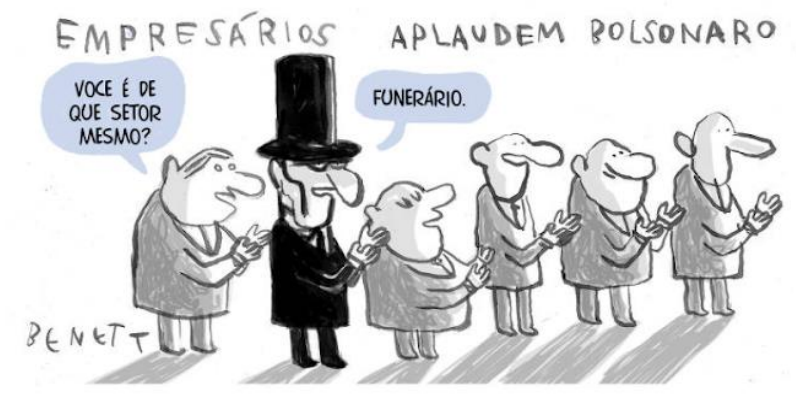

Fonte: https://fotografia.folha.uol.com.br/galerias/1695890190757786-charges-abril-2021. Acesso em 13 de mai. de 2021.

Nessa charge, a responsabilidade relacionada ao aumento do número de vítimas fatais decorrentes de complicações da Covid-19 no Brasil é atribuída ao presidente Jair Bolsonaro. Ao reiterar o discurso de que a economia não poderia estagnar devido à pandemia, Bolsonaro, diversas vezes, defendeu a flexibilização do isolamento social, o que, consequentemente, agravaria o problema relacionado à crise sanitária no país. No texto, a imagem de homens com terno, associada ao material verbal "empresários aplaudem Bolsonaro", veicula a ideia de que as ações governamentais beneficiariam as classes detentoras do capital, ao passo que a classe menos favorecida, ao voltar ao trabalho sem auxílio do governo, seria obrigada a se expor ao contágio pelo Sars-Cov-2, mesmo o país não tendo um plano adequado de vacinação ou infraestrutura hospitalar para atender aos infectados. Ademais, a vestimenta preta de uma das pessoas e a sua identificação como sendo do setor funerário corrobora a tese de que, na tentativa de salvar a economia, o presidente teria deixado de lado o compromisso de salvar vidas, conclusão a que só é possível se chegar se forem considerados diversos índices de interpretação, como o conhecimento do momento histórico representado pela charge, bem como as imagens e os subentendidos evocados.

Acerca dessa dinâmica de relacionar elementos internos e externos ao enunciado no processo de construção de sentido, Charaudeau (2018, p. 17) explica que as operações interpretativas são inferenciais: a inferência centrípeta interna seria processada por meio da mobilização de componentes presentes no enunciado; a inferência centrífuga externa, por sua vez, estaria relacionada com o apelo a conhecimentos exteriores ao enunciado. Segundo o autor, 
a convergência dessas duas atividades inferenciais é o que permitiria levantar hipóteses de interpretação. De forma esquemática, a figura a seguir representa a mecânica interpretativa: o processo inferencial centrífugo externo aponta para dados extralinguísticos, enquanto a ação inferencial centrípeta interna, em sentido oposto, focaliza os dados presentes na superfície textual:

Figura 2 - Esquema de operações interpretativas

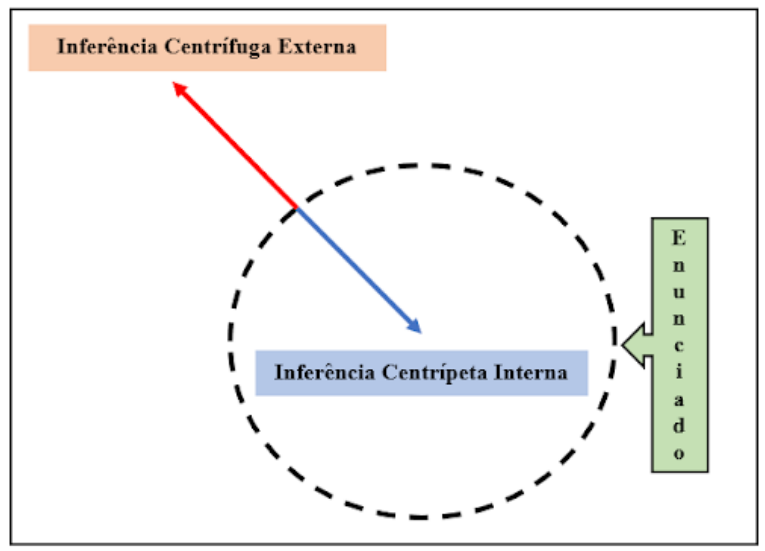

Fonte: Os autores (2021).

Dada a composição sucinta do gênero meme, acreditamos, pois, que o processo interpretativo que o envolve esteja ancorado, sobremaneira, nas inferências centrífugas externas, deflagradas por elementos intertextuais inscritos no enunciado, seja por meio de palavras, seja por meio de imagens.

Considerando categorias já recorrentemente estudadas no tratamento do discurso materializado em textos verbais, como a noção de contrato de comunicação, imaginários sociodiscursivos, modos de organização do discurso, entre outros, a Teoria Semiolinguística do Discurso vem sendo empregada por alguns autores, dentre eles Mendes (2013) e Silva e Marchon (2021), também, na análise de textos que associam materiais verbais e imagéticos. Todavia, conforme pondera Mendes (2013) acerca dessas investigações, é preciso levar em conta as características inerentes às imagens, como enquadres, planos, cores e ângulos aspectos esses que pretendemos discutir neste artigo, valendo-nos, para tanto, de alguns postulados da Teoria da Multimodal da Comunicação ${ }^{3}$.

Essa teoria, proposta por Kress e Van Leeuwen 2006 [1996], pressupõe que os sentidos são constituídos a partir da conjugação de diversos recursos semióticos, como imagens, palavras, sons e cores. A essa associação de diferentes modos de representação da linguagem,

\footnotetext{
${ }^{3}$ Devido ao limite de espaço deste artigo, apresentaremos os postulados teóricos de Kress e van Leeuwen (2006 [1996]) por nós mobilizados na seção seguinte, juntamente com nossas propostas de análise dos memes.
} 
os autores chamam de multimodalidade - "[...] qualquer texto em que os sentidos são realizados por meio de mais de um código semiótico"4 (KRESS; VAN LEEUWEN, 2006 [1996], p. 177). Nesse viés, como demonstramos anteriormente na análise da charge, os elementos de diferentes semioses que compõem o texto não são vistos como partes desconectadas, mas interligadas os sentidos emergem justamente da relação construída entre as modalidades ou semioses de naturezas distintas, tornando o texto um todo integrado, ponto de vista já reconhecido por outras vertentes dos estudos linguísticos, como confirmam Cavalcante e Custódio Filho (2010, p. 57):

\begin{abstract}
A afirmação óbvia de que o objeto de estudo da Linguística é a linguagem pode esconder a informação mais importante de que, na verdade, a investigação sobre a linguagem tem por meta tratar da temática dos sentidos. É a busca por desvendar as relações entre as formas e os sentidos, além de sua relação com a mente e com os aspectos contextuais, que está na raiz de quase todas as teorias linguísticas. Por isso é que estas só se sustentam se embasadas por pressupostos filosóficos (mesmo que não explicitados), e por isso é que há um constante diálogo entre a Linguística e outras ciências que cuidam dos sentidos, como a Semiótica (CAVALCANTE; CUSTÓDIO FILHO, 2010, p. 57).
\end{abstract}

A fim de discutirmos a relação entre elementos verbais e não verbais, apresentamos, na seção seguinte, algumas considerações sobre o meme, gênero discursivo constituído, em geral, por palavras e imagens.

\title{
Meme: um gênero multimodal e intertextual
}

A intertextualidade, considerada um dos grandes temas a que se têm dedicado tanto os linguistas da Linguística Textual quanto estudiosos da Análise do Discurso, é um recurso linguístico-discursivo que se refere à construção de novos textos e/ou de novos sentidos a textos que já foram construídos anteriormente, podendo, em nossa visão, figurar como importante estratégia argumentativa.

De acordo com o Dicionário de Análise do Discurso, "a intertextualidade designa, ao mesmo tempo, uma propriedade constitutiva de qualquer texto e o conjunto das relações explícitas ou implícitas que um texto ou um grupo de textos determinado mantém com outros" (CHARAUDEAU; MAINGUENEAU, 2008, p. 288). Nessa perspectiva, não há um texto autônomo e livre das interferências dos aspectos intertextuais e interdiscursivos - de acordo com Bakhtin (2003, p. 272), “cada enunciado é um elo na corrente complexamente organizada de outros enunciados", uma vez que todo discurso parte de outro existente. Seguindo essa linha de raciocínio, Authier-Revuz (1990, p. 25) afirma que "somente Adão mítico, abordando com

\footnotetext{
4 "any text whose meanings are realized through more than one semiotic code".
} 
sua primeira fala um mundo ainda não posto em questão, estaria em condições de ser ele próprio o produtor de um discurso isento da fala do outro.”.

No intuito de mostrar que nenhum discurso, portanto, é neutro, mas carregado, habitado, atravessado e ocupado pelos discursos alheios, nosso corpus de análise é constituído por seis memes constituídos por material verbal e imagético sobre questões políticas nacionais da contemporaneidade, cotejados do Google Imagens. Mais especificamente, buscaremos discutir como a argumentação é construída nesse gênero que exige a leitura de imagens e palavras, bem como o conhecimento de outros textos.

Sobre o gênero meme, cumpre esclarecer que ele é intertextual por natureza - o próprio termo meme remete à memória, à mimesis. Em outras palavras, a existência do gênero meme pressupõe a imitação de modelos. De acordo com informações do Museu de Memes - acervo digital da Universidade Federal Fluminense com levantamento bibliográfico de artigos, livros e trabalhos científicos sobre o universo desse gênero -, o termo meme foi empregado pela primeira vez em 1976, quando Richard Dawkins, biólogo especializado em comportamento social, propôs o rótulo para dar conta dos processos de replicação e evolução cultural.

\footnotetext{
Dawkins concebe uma espécie de evolucionismo cultural, que ocorreria em paralelo e em complemento à evolução natural, através de um segundo replicador, diferente dos genes. Não tendo encontrado outro nome mais adequado para batizá-lo, o biólogo adaptou a raiz grega "mimeme" (imitação) e criou o termo "meme".

(...)

Na definição original de Dawkins, memes são ideias que se propagam pela sociedade e sustentam determinados ritos ou padrões culturais. (https://www.museudememes.com.br/o-que-sao-memes/. Acesso em: 8 de mai. de 2021)
}

Desde a proposta de Dawkins, diversos estudiosos têm empregado e atualizado o conceito. Somente, porém, no final da década de 1990, os memes, como hoje os conhecemos, difundiram-se na internet, apresentando-se sob a forma de imagens legendadas, vídeos virais ou expressões veiculadas nas redes sociais. Dada sua natureza intertextual, esses textos têm, em sua gênese, a relação com algum fato deflagrado recentemente pela mídia, o que os torna, também, um gênero marcado pela efemeridade.

A título de ilustração, analisemos o meme a seguir, constituído apenas por imagens: do lado esquerdo, o ex-ministro da saúde, Nelson Teich; do lado direito, o apresentador do Big Brother Brasil, Tiago Leifert. 
Figura 3 - Meme Eliminação do Ministro da Saúde do governo Bolsonaro

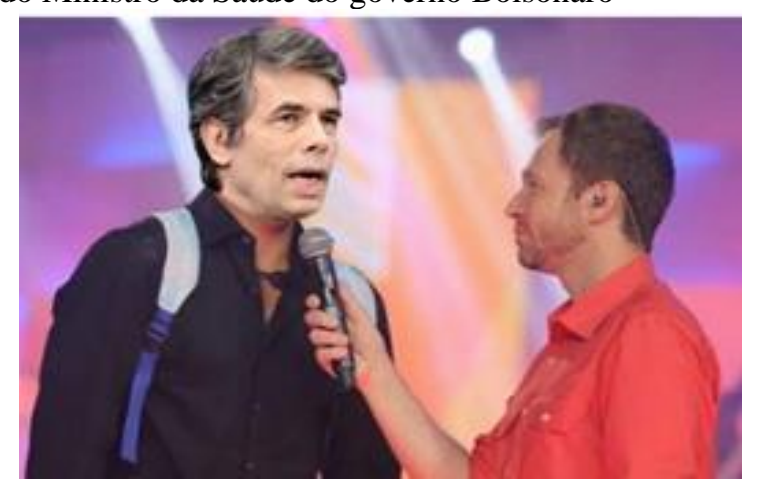

Fonte: https://extra.globo.com/tv-e-lazer/saida-do-ministro-nelson-teich-gera-memes-nas-redes-sociais-vejareacoes-24430026.html. Acesso em: 30 de abr. de 2020.

A imagem da interação dessas personalidades brasileiras remonta o momento em que um dos participantes, por decisão do público, é eliminado do reality show Big Brother Brasil. A mochila nas costas e a tradicional entrevista com o eliminado funcionam como deflagradores da crítica veiculada pelo meme: Teich, médico oncologista, foi eliminado do governo Bolsonaro, em plena pandemia da Covid-19, por, possivelmente, discordar dos posicionamentos polêmicos do presidente que iriam contra as determinações da Organização Mundial da Saúde no que tange ao combate à propagação do vírus. Em outras palavras, o enunciador coloca em xeque a competência técnica do presidente ao desconsiderar avaliações de profissionais especializados.

Na figura 4 a seguir, além dos elementos imagéticos, temos o emprego de elementos verbais:

Figura 4 - Meme Nazaré Tedesco rouba pacote de arroz.

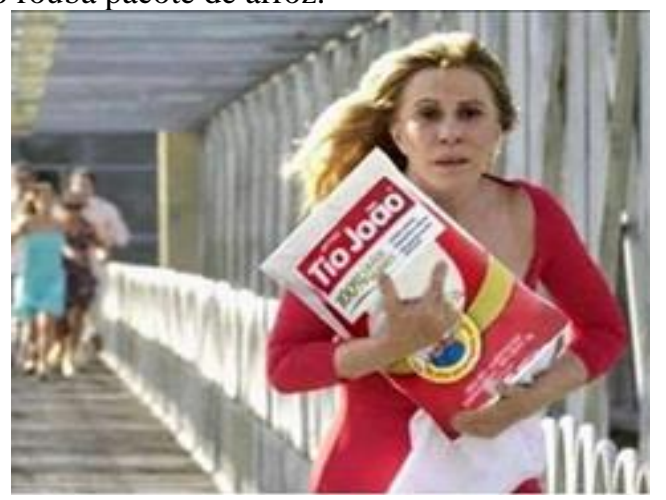

Fonte: https://oglobo.globo.com/economia/financiado-ou-sequestrado-arroz-mais-caro-alimenta-memes-piadasnas-redes-sociais-24633758. Acesso em: 30 de abr. de 2021.

Nesse meme, a famosa vilã Nazaré Tedesco, interpretada pela atriz Renata Sorrah, foge com um pacote de arroz da marca Tio João, dado o elevado preço atingido pelo cereal em 2020, no Brasil. Esse texto pode ser interpretado como uma crítica às políticas governamentais de 
gerenciamento de importação e exportação do produto no país. Na ocasião, Jair Messias Bolsonaro, minimizando a crise, chegou a dizer, em uma de suas entrevistas, que o brasileiro deveria substituir esse alimento por outro tipo de carboidrato, como o macarrão, sem prejuízo à dieta alimentar balanceada.

No que se refere ao segundo meme, podemos dizer, nos termos de Garcia (2020), que se trata de um caso de intertextualidade multimodal, uma vez que a remissão a textos outros é feita por meio da coocorrência integrada de mais de um modo de construção da linguagem (semioses), ou seja, palavra e imagem, neste caso. Dentro da perspectiva teórica adotada neste trabalho, assumimos que a intertextualidade multimodal pode funcionar como uma estratégia argumentativa, como discutiremos na seção a seguir.

\title{
Intertextualidade multimodal: uma estratégia argumentativa
}

Amossy (2016) salienta que a argumentação é inerente a todo e qualquer discurso. Para a autora, há textos dotados de visada argumentativa que se organizam por sequências argumentativas claramente identificáveis, tal qual definida por Adam (2019), e textos que, apesar de não serem composicionalmente argumentativos, apresentam uma dimensão argumentativa, isto é, uma tentativa de o enunciador agir sobre o interlocutor.

\begin{abstract}
A noção de argumentação aqui recebe uma extensão máxima na medida em que abrange tanto os gêneros do discurso que explicitamente defendem ou refutam uma tese, quanto aqueles que se contentam em orientar os modos de ver e de pensar. Toda fala tende a fazer compartilhar um ponto de vista, uma forma de reagir a uma situação ou de sentir um estado de fato. Os esquemas de raciocínio são, neste caso, mais ou menos elaborados e mais ou menos visíveis. Muitas vezes, a orientação dada ao discurso aparece nos traços da linguagem (modalidades, formas axiológicas, conectores, etc.) sem que emerja, para tanto, um argumento formal. Às vezes, este argumento enuncia-se apenas sob uma forma elíptica e necessita do recurso ao interdiscurso para poder ser reconstruído (AMOSSY, 2016, p. 174).
\end{abstract}

Na esteira do raciocímio de Amossy (2016), portanto, defendemos que o meme figura no rol dos gêneros argumentativos, tendo em vista que é marcado por um evidente caráter persuasivo, como veremos mais adiante. Mesmo o meme não apresentando as sequências argumentativas a que a autora faz menção, dadas as particularidades de sua composição multissemiótica, defendemos, conforme Silva e Marchon (2021), que é exatamente na junção das diferentes semioses que a argumentação é construída.

Nossa proposta de análise, portanto, além de se pautar nos princípios da Teoria Semiolinguística do Discurso no que tange à argumentação, buscará respaldo também em 
alguns ensinamentos de Kress e van Leeuwen (2006 [1996]), no que concerne à sintaxe da imagem.

Como pontuam Kress e van Leeuwen (2006 [1996]), à similitude da gramática verbal, que descreve a formação das palavras, bem como a combinação dessas em orações, complexos oracionais e textos, a gramática visual descreverá a maneira como os elementos representados se combinam em declarações visuais e as regularidades das estruturas de composição, e também de que modo são utilizadas na produção de significados (SANTOS, 2020, p. 96).

Na Gramática do Design Visual (doravante, GDV), proposta por Kress e Leeuwen, há três domínios semânticos de descrição e análise: representação, interação e composição. Nossa análise da construção argumentativa se baseia nesses domínios, que são elencados a seguir.

O domínio da representação é aquele em que se verificam as imagens que constituem o texto visual. Os agentes internos ao texto são chamados de Participantes Representados, enquanto os da comunicação são os Participantes Interativos. Nessa metafunção representacional, duas estruturas podem ser observadas: (i) a narrativa, atribuída a imagens nas quais se percebe um vetor de direcionalidade, e (ii) a conceitual, referente a estruturas estáticas, em que não há um vetor.

Um texto em que se pode perceber o uso da intertextualidade multimodal como estratégia argumentativa com uma estrutura narrativa é o meme da figura 5 a seguir:

Figura 5 - Meme cepa in Rio

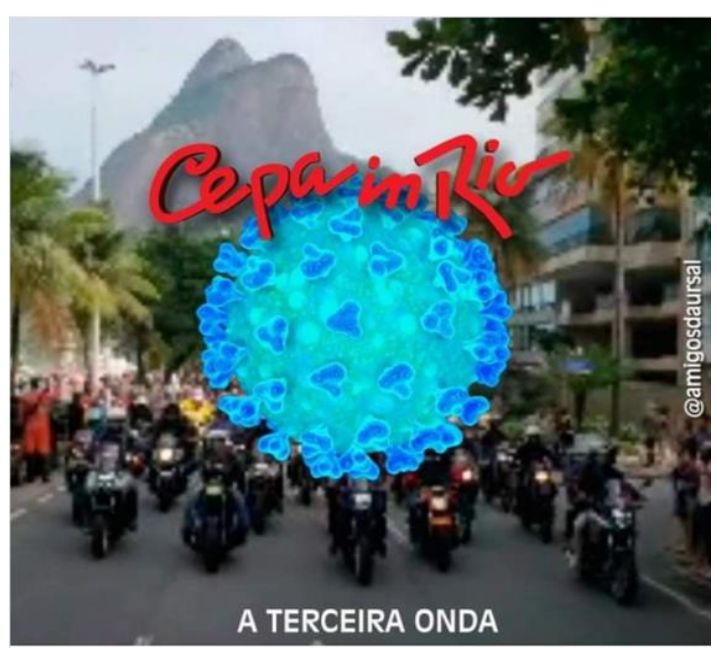

Fonte: Google Imagens. Acesso em: 27 de mai. de 2021.

Em 23 de maio de 2021, ainda durante a grave crise de saúde pública causada pela pandemia de Covid-19, o presidente do Brasil, alheio às orientações científicas para a prevenção da doença, participou de uma motociata com apoiadores na cidade do Rio de Janeiro. A maioria dos participantes do evento, incluindo o presidente, não usava máscara, item essencial no 
combate à propagação do coronavírus. A partir desse evento deflagrador, o texto da figura 5 estabelece uma relação intertextual com o logotipo e o slogan da marca Rock in Rio. Assim, observamos que, com o mesmo estilo de letra e com a mesma cor do texto-fonte, lemos o termo "cepa", em lugar de "Rock", uma referência às mutações pelas quais o vírus passa, e "a terceira onda", em vez de "por um mundo melhor", uma referência ao crescimento exponencial do número de casos e mortes por Covid-19. Por seu formato esférico, a imagem do globo com uma guitarra, por sua vez, é substituída por uma representação do vírus Sars-Cov-2.

Uma análise a partir da associação de pressupostos da Semiolinguística e da Teoria Multimodal da Comunicação permite afirmar que as escolhas do enunciador visam a influenciar o seu interlocutor de que a manifestação dos motociclistas é uma forma de espalhar as novas cepas de coronavírus e induzir uma terceira onda da doença. Assim, a metafunção representacional desse texto possui uma estrutura narrativa, já que o vetor da posição dos motociclistas e da cepa indica movimento. O enunciador, portanto, em seu projeto de argumentação, estabelece uma relação de causalidade, nos termos de Charaudeau (2016), entre a motociata e o início da terceira onda da Covid-19 no Brasil.

No meme a seguir, entendemos que, do ponto de vista da representação, há uma estrutura conceitual, pois os lados direito e esquerdo estão relacionados a ideologias políticas: Lula, representante do Partido dos Trabalhadores, tradicionalmente de esquerda; o ex-juiz Sérgio Moro, representante da direita política brasileira.

Figura 6 - Meme Placar do julgamento de Lula no STF

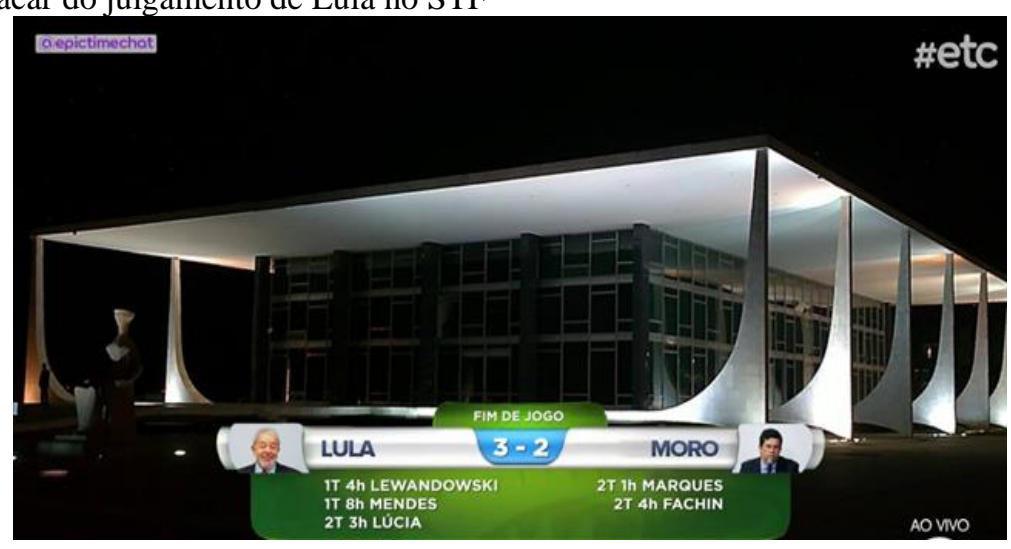

Fonte: Google Imagens. Acesso em: 24 de mar. de 2021.

Essa estratégia de composição discursiva é um exemplo de intertextualidade multimodal, pois vincula o resultado do julgamento em que o petista era réu a uma partida de futebol, por meio do placar similar aos dos utilizados em jogos. Nesse sentido, podemos dizer que o projeto argumentativo do enunciador é colocar Lula e Moro como adversários. Os votos 
favoráveis ou contrários à elegibilidade do ex-presidente são indicados pelos nomes dos ministros do Supremo Tribunal Federal, que representam, nesse meme, os atletas que marcam gols para cada uma das equipes. Considerando o evento deflagrador de produção desse discurso, podemos assumir que há, nos termos de Kress e van Leeuwen (2006 [1996]), a representação de uma estrutura conceitual de classificação de vencedores e perdedores, além da mencionada referência ao espectro político dos representados. Ressaltamos, todavia, que a identificação dessa estrutura conceitual, bem como o desvelamento do projeto argumentativo do enunciador na composição dos memes, só é possível se consideradas as peculiaridades de produção do discurso.

O domínio da interação, por sua vez, é o que se estabelece a relação entre Participante Representado (PR) e Participante Interativo (PI) por meio: (i) do contato, que se vincula ao olhar direto do PR ao PI (oferta) ou não direto (demanda); (ii) da distância social, a qual se representa pelo plano da imagem fechado (proximidade) ou aberto (distanciamento); (iii) da perspectiva, que pode ser de envolvimento (imagem frontal) ou de poder (imagem oblíqua) e (iv) da modalidade, a qual remete à realidade percebida na imagem (real ou irreal).

Para efeitos de análise, consideremos o seguinte contexto: no dia 17 de janeiro de 2021, após a Agência Nacional de Vigilância Sanitária (ANVISA) aprovar o uso emergencial da vacina Coronavac, desenvolvida pelo Instituto Butantan ${ }^{5}$ em parceria com o laboratório chinês Sinovac, foi iniciada a campanha de vacinação contra a Covid-19 no Brasil. Contudo, o percurso até esse evento não foi politicamente estável, uma vez que, conforme divulgado amplamente na imprensa brasileira, há indícios de que houve tentativas de sabotagem ao processo de desenvolvimento de um imunizante nacional. Nesse contexto, várias afirmações do Presidente da República podem ser consideradas entraves ao início da vacinação. Assim, no meme da figura 7 a seguir, o enunciador, em tom irônico próprio do gênero discursivo em estudo, veicula o discurso de que o início da campanha de imunização contra a Covid-19 é uma afronta ao presidente.

\footnotetext{
${ }^{5}$ O Instituto Butantan é um importante centro público de pesquisa biológica, localizado no estado de São Paulo. Pelo reconhecido trabalho em saúde pública, o instituto é considerado um dos principais centros científicos do mundo.
} 
Figura 7 - Meme primeira vacinada no Brasil

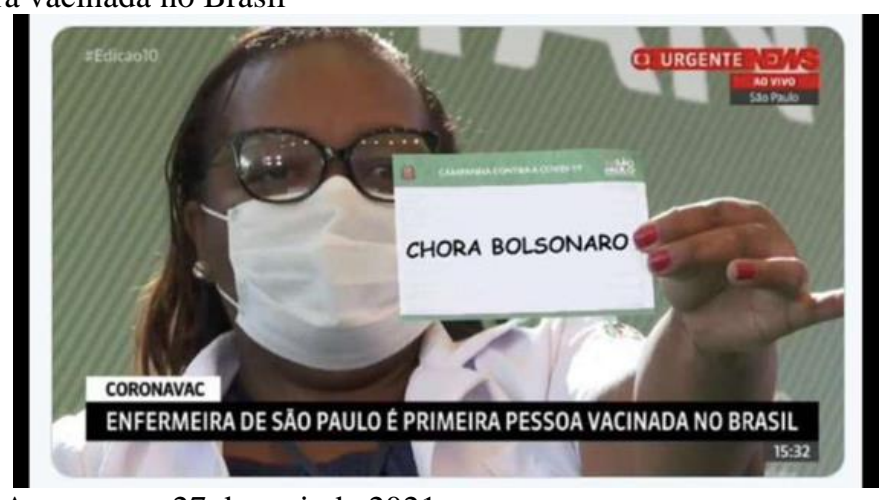

Fonte: Google Imagens. Acesso em: 27 de mai. de 2021.

No meme em questão, a intertextualidade multimodal é empregada como um recurso utilizado para a construção argumentativa. A partir da edição de uma captura de imagem de uma emissora de televisão, o enunciador constrói o texto, em que, no lugar das especificações da caderneta de vacinação da enfermeira Mônica Calazans, primeira pessoa que foi vacinada no país, há a frase "Chora Bolsonaro". Nesse sentido, podemos considerar a existência de uma intertextualidade multimodal na medida em que a frase mencionada só tem sentido como elemento intertextual com a integração dela à imagem da enfermeira e às frases da TV. É interessante notar que também ocorre, nesse caso, um exemplo de intertextualidade intertextos (conforme KOCH; ELIAS, 2010; entre outros), pois o cartaz de protesto apresenta-se sob a forma da caderneta de vacinação.

Do ponto de vista da metafunção interativa, esse texto sugere: (i) um contato de oferta, já que o olhar da enfermeira se dirige ao interlocutor; (ii) uma aproximação entre a profissional de saúde e o leitor, por conta do fechamento da imagem de Mônica; (iii) uma perspectiva de envolvimento simétrico, dada a horizontalidade da imagem, e (iv) uma modalidade mais real devido ao fato de a representação se aproximar da realidade, na forma de uma fotografia. Dessa maneira, o enunciador deixa as marcas de aproximação para argumentar que a ciência superou o negacionismo do presidente e que, assim como a enfermeira vacinada, o leitor será imunizado. Conforme Charaudeau (2016), o enunciador, em seu discurso, precisa produzir um efeito de verdade, não comprovar uma dada verdade.

O meme a seguir (figura 8) é outro exemplo de como funciona a metafunção interativa. Em abril de 2021, foi instalada uma Comissão Parlamentar de Inquérito (CPI) no Senado brasileiro com o intuito de investigar possíveis responsabilidades em falhas no enfrentamento à pandemia de Covid-19 no país. Durante o depoimento da ex-secretária do Ministério da Saúde e médica Mayra Pinheiro, conhecida como Capitã Cloroquina, o senador Randolfe Rodrigues reproduziu um áudio da depoente em que ela afirma, entre outras coisas, que havia um objeto 
que representava o órgão reprodutor masculino ereto na entrada da Fiocruz, instituição de pesquisa responsável por produzir uma das vacinas contra a Covid-19 desenvolvidas no Brasil. Após a reprodução da mídia, o senador Randolfe questionava à médica se ela confirmava a assunção do áudio, quando foi interrompido pelo presidente da CPI, senador Omar Aziz, que disse que a Mayra Pinheiro tinha falado a palavra "tênis". No entanto, a própria depoente corrigiu o senador, afirmando que havia empregado, de fato, a palavra "pênis". Esse acontecimento repercutiu nas redes sociais e serviu como texto-fonte para a produção de diversos memes, entre os quais o representado na figura 8:

Figura 8 - Meme Omar Aziz e Mayra Pinheiro
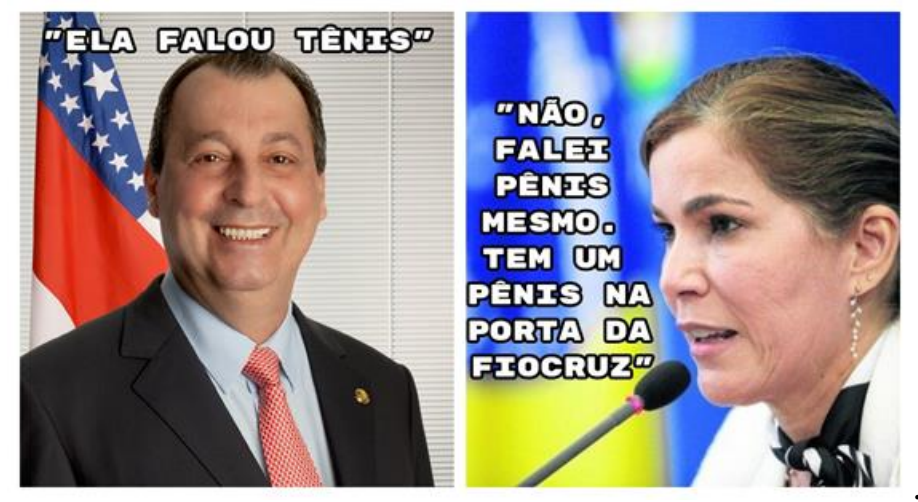

Fonte: Google Imagens. Acesso em: 27 de mai. de 2021.

Nessa construção, no plano da interação, além da modalidade mais real, dado que as imagens usadas são fotos do senador e da médica, percebemos que os vetores horizontais que indicam a direção de seus olhares também são empregados como estratégia de construção de sentido: enquanto a figura escolhida de Omar Aziz sugere uma aproximação entre o senador e o interlocutor, visto que seu olhar é direcionado ao observador do meme, verifica-se um certo distanciamento entre a médica e o leitor: na imagem de perfil de Mayra Pinheiro, os vetores horizontais apontam para a figura de Omar, forjando a estrutura narrativa do texto por meio do diálogo entre os participantes. Além desse distanciamento entre a médica e o leitor, no plano da interação, ressaltamos que, no plano da composição, o fechamento de imagem, aliado à maior quantidade de elementos verbais apresentados no quadro da depoente está, nesta situação de comunicação, relacionado ao objetivo do enunciador de enfatizar o lado negativo da preocupação da ex-secretária do Ministério da Saúde, que deveria se focar no combate à pandemia, não nas analogias feitas entre a arquitetura do prédio da Fiocruz e o órgão reprodutor masculino. A construção de sentido desse texto, portanto, passa pela convergência de inferências externas e inferências internas (CHARAUDEAU, 2018) - as últimas deflagradas, simultaneamente, por imagens e por palavras. Ao remontar esse episódio, no mínimo bizarro 
da CPI, o emprego da intertextualidade multimodal atua como estratégia de crítica à situação representada.

Por fim, considerando o domínio da composição (KRESS; VAN LEEUWEN, 2006 [1996]) , o analista observa a organização dos elementos no texto, de acordo com: (i) o valor da informação, valor esse que pode ser verificado pela disposição dos elementos na imagem, que pode representar os pares real/ideal, dado/novo e central/periférico; (ii) a saliência, que se refere à ênfase dada aos elementos da imagem uns em relação aos outros, e (iii) a moldura, que se relaciona à presença ou não de linha divisória entre as partes do texto multimodal.

Quanto ao domínio semântico da composição, de acordo com os autores da GDV, na construção da dimensão visual de um texto, a posição que um elemento ocupa na imagem é determinante na maneira como ele se relaciona com os outros componentes imagéticos. Essa característica lhe confere valores específicos na construção de sentido do texto visual ou do texto constituído por material verbal e não verbal. Dessa forma, é necessário descrever a posição do elemento em termos de esquerda e direita, acima e abaixo, centro e margem, como procedemos na análise do meme 9 a seguir:

Figura 9 - Meme Os Simpsons e a política brasileira na pandemia

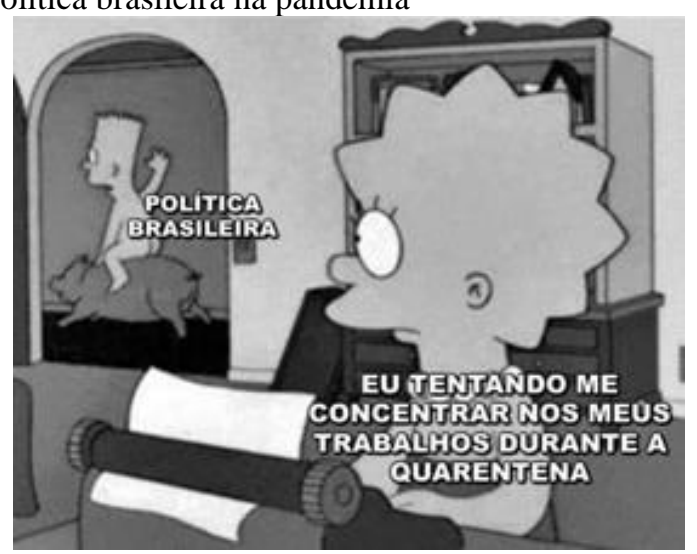

Fonte: Google Imagens. Acesso em: 22 de mar. de 2021.

Para efeitos de análise, propomos traçar uma linha imaginária vertical que divide a imagem em duas partes: do lado esquerdo, vemos o filho mais velho dos Simpsons, Bart, desnudo montado em um porco em movimento, com a legenda "política brasileira"; do lado direito, a legenda "eu tentando me concentrar nos meus estudos durante a quarentena" acompanha a imagem de Lisa Simpson, sentada à frente de uma máquina de escrever olhando, com espanto, a cena do irmão com o animal. De acordo com Kress e van Leeuwen (2006 [1996]), os elementos posicionados à esquerda são interpretados como informação dada, ou seja, informações compartilhadas pelos interlocutores; o lado direito da imagem, por seu turno, 
apresenta informações novas, isto é, desconhecidas ou que mereçam destaque. Dito isso, o jogo argumentativo engendrado pelo enunciador no meme em apreço focaliza o já conhecido descompasso da política brasileira em meio a crises - numa relação intertextual, Bart, um garoto problemático e sempre envolvido em confusão, é comparado ao governo; sua ação de cavalgar sem roupa em um porco dentro de casa traduz as ações governistas descompassadas no combate à pandemia. Por sua vez, Lisa, a menina estudiosa e sempre em busca de saber mais sobre o mundo, é afetada pela desordem da casa - nesse meme, seu incômodo reflete as consequências da falta de articulação do governo para minimizar os problemas decorrentes da pandemia.

Quanto à divisão horizontal da imagem, de acordo com a GDV, os elementos que ocupam a parte superior são classificados como ideais e representam a parcela mais abstrata da informação veiculada, ao passo que os elementos localizados na parte inferior são classificados como reais e materializam a concretude da informação veiculada. Seguindo esse viés de análise, podemos dizer que, no meme a seguir (figura 10), o enunciador, num tom irônico característico do gênero, tece críticas à corrupção que rondaria a família Bolsonaro.

Figura 10 - Meme Better call Wassef

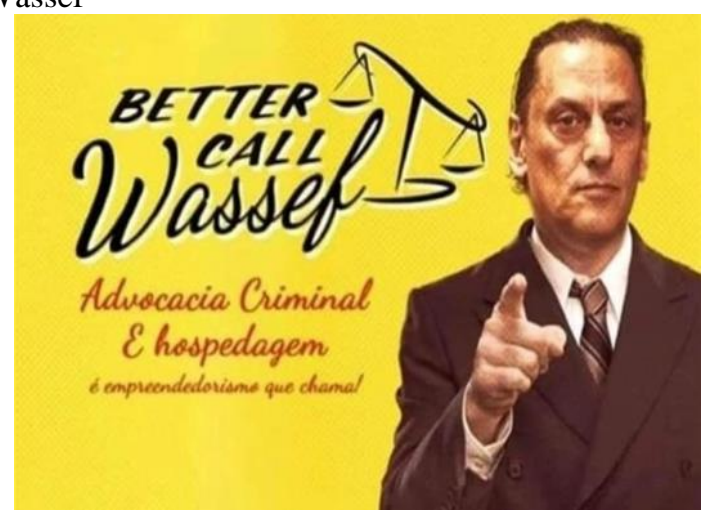

Fonte: Facebook. Acesso em: 23 de jun. de 2021.

A imagem de Frederick Wassef, advogado da família do presidente, direcionando o olhar e o dedo para o leitor do meme, associada ao material verbal better call Wassef e aos arranjos gráficos relacionados ao formatos das letras e à cor de fundo, deflagra a relação intertextual do meme com a série de televisão americana Better call Saul: tal como Saul, o advogado do seriado, Wassef empregaria táticas ilegais e empreenderia esquemas criminosos para beneficiar os clientes que teriam problemas com a lei.

Mais especificamente, o meme 10 faz alusão à prisão de Fabrício Queiroz, ex-assessor e ex-motorista do Senador Flávio Bolsonaro, uma peça-chave no processo que investiga desvios de dinheiro público praticados no gabinete de Flávio. Queiroz, depois de mais de um ano foragido da justiça, foi encontrado em Atibaia, em um imóvel de Wassef, o que explica o 
enunciado "Advocacia Criminal e hospedagem" localizado na parte inferior do texto, remetendo, pois, à face mais concreta e, pode-se dizer, inquestionável das informações veiculadas. Dito de outra forma, o "empreendedorismo" de Wassef foi esconder, em sua casa no interior de São Paulo, a testemunha que poderia incriminar o Senador.

Sobre a atuação de ações linguísticas, cognitivas e sociais mobilizadas para os memes aqui analisados, destacamos a consideração de Cavalcante (2010, p. 9):

A produção de linguagem verbal e não verbal constitui atividade interativa altamente complexa de produção de sentidos que se realiza, evidentemente, com base nos elementos presentes na superfície textual e na sua forma de organização, mas que requer não apenas a mobilização de um vasto conjunto de saberes (enciclopédia), mas a sua reconstrução e a dos próprios sujeitos - no momento da interação verbal.

Neste artigo, consideramos essa complexidade que envolve a produção de sentido e, apoiados em Charaudeau (2009), tomamos a argumentação como a tentativa de levar o outro, o interlocutor, a aderir a uma determinada ideia, ou a fazer ou sentir algo, e não apenas a argumentação como sinônimo de raciocínio demonstrativo.

\section{Palavras Finais}

Este trabalho, dadas suas próprias limitações, não abarca a totalidade do fenômeno apresentado, afinal, debruçamo-nos apenas sobre um tipo de multimodalidade: a que leva em conta a junção do material verbal com o material imagético em uma relação intertextual (GARCIA, 2020). Nesse sentido, apresentamos um estudo em que, sob o pressuposto de que todas as atividades linguageiras são formas de o enunciador agir sobre o seu interlocutor (CHARAUDEAU, 2009), analisamos, a partir de elementos da GDV, proposta por Kress e Van Leeuwen (2006 [1996]), como o fenômeno da intertextualidade multimodal atua como uma estratégia argumentativa. Em outras palavras, procuramos demonstrar, nos termos de Silva e Marchon (2021), que a dimensão argumentativa de um texto pode ser engendrada pelo emprego estratégico de diferentes modalidades.

Por meio das análises apresentadas, observamos que, no gênero meme, a imagem agrega sentidos que faltam aos enunciados linguísticos e vice-versa - esta relação entre palavra e imagem foi chamada por Barthes (1990) de relais; Santaella (2012) denomina de relação semântica por complementariedade, ressaltando que imagem e palavras têm a mesma importância na construção do sentido, sendo, pois, indissociáveis. Neste caso, a intencionalidade argumentativa é materializada pela junção das diferentes semioses, em um 
processo de interdependência, que convoca processos inferenciais externos e internos à superfície textual, para que o fenômeno da intertextualidade multimodal seja reconhecido e cumpra a função de ser mais um recurso de que o enunciador dispõe para a construção da argumentação.

\section{Referências}

ADAM, J. M. Textos: tipos e protótipos. São Paulo: Contexto, 2019.

AUTHIER-REVUZ, J. Heterogeneidade (s) enunciativa (s). Cadernos de Estudos Linguísticos, Campinas, n. 19, p. 25-42, 1990.

AMOSSY, R. É possível integrar a argumentação na análise do discurso? Problemas e desafios. Trad. Rosalice Pinto, Mariza Angélica Paiva Brito e Meire Virgínia Cabral Gondim. ReVEL, edição especial, v. 14, n. 12, p. 165-190, 2016.

BAKHTIN, M. Estética da criação verbal. Trad. Paulo Bezerra. São Paulo: Martins Fontes, 2003.

BARTHES, R. O óbvio e o obtuso: ensaios críticos III (L. Novaes, Trad.). Rio de Janeiro, RJ: Nova Fronteira, 1990.

BENVENISTE, E. Problemas de linguística geral II. 2. ed. Campinas: Pontes Editores, 2006.

CAVALCANTE, M. M.; CUSTÓDIO FILHO, V. Revisitando o estatuto do texto. Revista do GELNE, v. 12, n. 2, p. 56-71, 2010.

CHARAUDEAU, P. Linguagem e discurso: modos de organização. São Paulo: Contexto, 2009.

CHARAUDEAU, P.; MAINGUENEAU, D. Dicionário de Análise do Discurso. São Paulo: Contexto, 2008.

CHARAUDEAU, P. A argumentação em uma problemática da influência. ReVEL, edição especial, v. 14, n. 12, 2016.

CHARAUDEAU, P. Compreensão e interpretação: Interrogação em torno de dois modos de apreensão do sentido nas ciências da linguagem. Site Ciad-Rio, 2018. Disponível em: https://ciadrj.letras.ufrj.br/. Acesso em: 10 jun. 2021.

ELIAS, V. M. Estudo do texto, multimodalidade e argumentação: perspectivas. ReVEL, edição especial, v. 14, n. 12, 2016.

GARCIA, C. E. N. Intertextualidade multimodal. Diacrítica, v. 34, n. 1, p. 122-134, 2020. Disponível em: http://diacritica.ilch.uminho.pt/index.php/dia/article/view/352. Acesso em: 31 mai. 2021. 
KOCH, I. V. A inter-ação pela linguagem. 10. ed. São Paulo: Contexto, 2008.

KOCH, I. V.; ELIAS, V. M. Ler e compreender: os sentidos do texto. 3. ed. São Paulo: Contexto, 2010.

KRESS, G.; VAN LEEUWEN, T. Reading images: the grammar of visual design. London: Routledge, 2006 [1996].

MARCHON, A. H. GARCIA, C. E. N. Intertextualidade multimodal como estratégia argumentativa: uma leitura de memes do Facebook. In: Pré-Anais da III Jornada Internacional Semântica e Enunciação, 2021, Campinas. Anais eletrônicos... Campinas, Galoá, 2021. Disponível em: https://proceedings.science/jise-2021/papers/intertextualidade-multimodalcomo-estrategia-argumentativa---uma-leitura-de-memes-do-facebook. Acesso em: 27 abr. 2021.

MENDES, E. Análise do Discurso e iconicidade: uma proposta teórico-metodológica. In: MENDES, E. (Coord.); MACHADO, I. L.; LIMA, H.; LYSARDO-DIAS, D. (Org.). Imagem e discurso. Belo Horizonte: FALE/UFMG, 2013. p. 125-156.

SANTAELLA, L. Leitura de imagens (Coleção Como eu ensino). São Paulo, SP: Melhoramentos, 2012.

SANTOS, W. Q. A gramática das construções mêmicas de internet no português do Brasil: uma interface da gramática sistêmico-funcional e da gramática do design visual. 2020. 186 f. Doutorado (Tese) - Universidade Federal de São Carlos, São Carlos.

SILVA, W. P.; MARCHON, A. H. Argumentação multimodal: uma proposta teóricometodológica. Revista Acta Scientiarum Language and Culture. Maringá, 2021 (no prelo).

\section{Sobre os autores}

Amanda Heiderich Marchon (Orcid iD: https://orcid.org/0000-0002-6576-949X)

Possui graduação em Letras - Língua Portuguesa e Literaturas de Língua Portuguesa - pela Faculdade de Filosofia Santa Dorotéia, mestrado e doutorado em Letras Vernáculas pela Universidade Federal do Rio de Janeiro. Atualmente, desenvolve pesquisa de pós-doutorado em Estudos da Linguagem na Universidade Federal Fluminense sob a supervisão da Professora Doutora Nilza Barrozo Dias. É Professora Adjunta do Departamento de Línguas e Letras da Universidade Federal do Espírito Santo e professora permanente do Programa de PósGraduação em Linguística da mesma universidade. É membro do GT da ANPOLL Linguística de Texto e Análise da Conversação. É lider do grupo PorUs-UFES (CNPq-UFES) e atua como pesquisadora do CIAD-Rio (CNPq-UFRJ) e do Grupo Protexto (CNPq-UFC). Trabalha, principalmente, com os seguintes temas: argumentação; discurso midiático; multimodalidade; articulação de orações. 
Carlos Eduardo Nunes Garcia (Orcid iD: https://orcid.org/0000-0002-9112-7490)

Possui graduação em Letras - Língua Portuguesa e Literaturas de Língua Portuguesa e mestrado em Letras Vernáculas pela Universidade Federal do Rio de Janeiro, instituição em que atualmente cursa o doutorado. É professor do CEFET/MG, campus Leopoldina. Tem interesse na área de sintaxe e na área de linguagem e tecnologia, especialmente na relação entre multimodalidade e ensino.

Recebido em junho de 2021.

Aprovado em julho de 2021. 